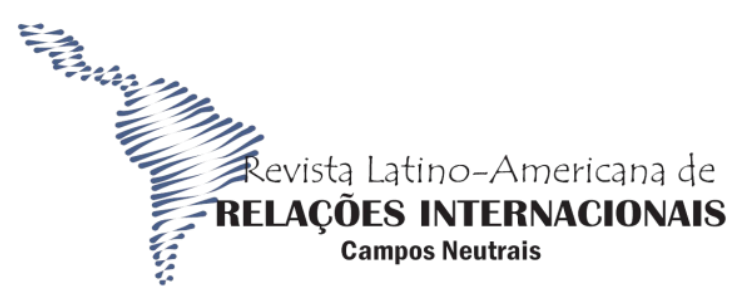

FURG

\title{
POR QUE WEBER É UM PENSADOR TRÁGICO?
}

José Renato Ferraz da Silveira

\begin{abstract}
Resumo: Max Weber é um dos principais nomes da sociologia moderna. Economista, sociólogo, filósofo alemão, ele realizou diversos estudos de história comparativa e foi um dos autores mais influentes do estudo do capitalismo, da burocracia e da religião. O erudismo e a massa colossal de conhecimentos produzidos por Weber revelam a agudeza e a rara capacidade de apreensão da sua mente. O presente ensaio aborda a visão trágica do autor acerca da política e considera-o um expoente do pensamento trágico. Weber se apropriou das obras de Nietzsche e Simmel para revelar a inevitabilidade do conflito, os paradoxos, os dilemas, as tensões, a força do imponderável, a inescapável oscilação entre o desejável e o possível no reino da política. Consideramos que o ensaio contribui em revisitar e repensar um autor clássico sob uma perspectiva inovadora, renovadora e fecunda para o pensamento sociológico e político.
\end{abstract}

Palavras-chave: Max Weber. Trágico. Filosofia. Política. Poder.

\section{WHY IS WEBER A TRAGIC THINKER?}

Abstract: Max Weber is one of the leading names in modern sociology. An economist, sociologist and philosopher, the German theoretician conducted several studies in comparative history and was one of the most influential authors to study capitalism, bureaucracy and religion. The erudition and the colossal amount of knowledge he produced reveal the sharpness and rare grasping ability of his mind. This essay addresses the author's tragic view of politics and considers him an exponent of tragic thinking. Weber appropriated the works of Nietzsche and Simmel to reveal the inevitability of conflict, the paradoxes, dilemmas, tensions, the power of the imponderable, and the inescapable oscillation between the desirable and the possible within the realm of politics. We consider that this essay contributes by revisiting and rethinking a classic author from a perspective that is innovative, refreshing and fruitful to sociological and political thinking.

Keywords: Max Weber. Tragic. Philosophy. Politics. Power.

\section{¿POR QUÉ WEBER ES UN PENSADOR TRÁGICO?}

Resumen: Max Weber es uno de los principales nombres de la sociología moderna. Economista, sociólogo, filósofo alemán, él realizó diversos estudios de historia comparativa y fue uno de los autores más influyentes del estudio del capitalismo, de la burocracia y de la

\begin{tabular}{|c|c|c|c|c|}
\hline $\begin{array}{l}\text { CAMPOS NEUTRAIS } \\
\text { REVISTA LATINO-AMERICANA DE RELAÇÕES INTERNACIONAIS }\end{array}$ & Rio Grande & v. 3, n. 2 & p. $143-154$ & Maio-Ago 2021 \\
\hline
\end{tabular}


religión. El eruditismo y la masa colosal de conocimientos producidos por Weber revelan la agudeza y la rara capacidad de aprehensión de su mente. El presente ensayo aborda la visión trágica del autor acerca de la política y lo considera un exponente del pensamiento trágico. Weber se apropió de las obras de Nietzsche y Simmel para revelar la inevitabilidad del conflicto, las paradojas, los dilemas, las tensiones, la fuerza de lo imponderable, la inexcusable oscilación entre lo deseable y lo posible en el reino de la política. Consideramos que el ensayo contribuye el revisitar y repensar un autor clásico bajo una perspectiva innovadora, renovadora y fecunda para el pensamiento sociológico y político.

Palabras-clave: Max Weber. Trágico. Filosofía. Política. Poder.

\title{
Introdução
}

\begin{abstract}
"Na segunda feira, 14 de junho, o mundo lá fora aquietou-se; somente uns tordos cantavam sem cessar seu canto de saudade. $O$ tempo parou. No final da tarde, Weber deu o último suspiro. Enquanto morria, caía uma tempestade e relâmpagos iluminavam sua cabeça pálida. Ele parecia a imagem de um cavaleiro morto. Sua face denotava suavidade e elevada renúncia. Ele partiu para algum lugar distante, inacessivel. A terra mudou”" (DIGGINS, 1999, p. 317).
\end{abstract}

\section{1) O caleidoscópio, o mosaico chamado Weber}

É consenso entre os especialistas que as teorias de Weber não se identificam com nenhuma corrente de pensamento de sua época nem se encontram perfeitamente sistematizadas numa grande obra.

Weber teve uma produção profícua em diversas áreas das ciências humanas: arte, religião, política, economia, trabalho e etc.

Escreveu acerca de uma infinidade de temas: Protestantismo, dominação, burocracia, ética, cultura, religiosidade, ciência, entre outros.

Os pensamentos de Weber parecem um caleidoscópio, um mosaico de cores, odores e sons. Ele deixou um legado vastíssimo para ler e reler. Estudar e pesquisar. Fundar e "refundar". Criar e recriar. Sistematizar e questionar. Debater e refletir. Inspirar e talvez posicionar.

É nessa linha de raciocínio que o filósofo Karl Jaspers escreveu: "Weber não tinha filosofia, ele era filosofia".

A filosofia de Weber, de fato, condensava sua biografia e seus conflitos com a vida. A vida, para ele, era um paradoxo. Alegria e tristeza. Começo e fim. Despertar e o 


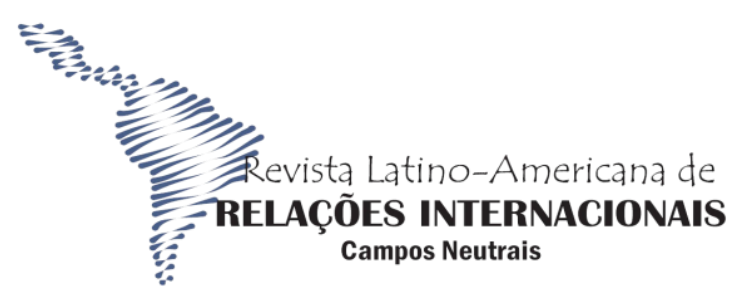

FURG

crepúsculo. Luz e trevas. Paz e fúria. Tudo convivendo misteriosamente. E em harmonia ou não.

\begin{abstract}
A filosofia social de Max Weber contém uma rica sucessão de pensamentos vivos que representam tanto seus conflitos com a vida como as contingências e dilemas não resolvidos da própria vida. Poder-se-ia dizer que Weber pensou mais como filósofo ou poeta do que como cientista social. Ele se preocupou com os indivíduos como pessoas em busca de sentidos e com a história como um drama de propósitos e destinos, vistos por uma lente obscura. Ele refletiu sobre a situação das instituições organizadas, cuja impermanência apontava para mudança e conflito, formação e desintegração, o passado como espetáculo humano de esperança e ruínas. A singular teoria e metodologia de Weber, por longo tempo apreciada como análise sociológica de temas acadêmicos familiares, é também uma meditação sobre o sentido. O estilo trágico de Weber, em vez de oferecer um ordenamento racional da sociedade, apresenta uma dramatização de suas antinomias conforme confronta as inúmeras operações do poder (DIGGINS, 1999, p. 89).
\end{abstract}

O pensamento de Weber tem intrínseca relação com a nossa vida marcada pelo desafio, conflito e dificuldade. "Um contemporâneo de Weber, Walter Lippmann afirmou que a filosofia do homem é sua biografia; você pode ler a história de seu conflito com a vida" (DIGGINS, 1999, p. 89).

Dessa forma, a visão de mundo de Weber refletia intensamente sua experiência familiar. Ainda de acordo com Diggins (1999, p. 68): "Weber cresceu levando consigo dualismos internos, tais como tensão entre a liberdade e o poder, a emoção e a razão, sendo que tais impulsos, divididos em sua mente e temperamento, eram como que reflexos de sua ascendência".

Pois bem, o pensamento de Weber aparece como uma verdadeira síntese da tradição científica e filosófica da Alemanha moderna. Ele é um autor polêmico. Sem dúvida, ele não tentou agradar aos leitores e críticos. Ele produziu sua obra a partir de seus "aplausos internos". Suas ideias políticas e religiosas, muitas vezes, foram questionadas por outros pensadores. Isso não o incomodou. Ele seguiu em frente. E é a partir dessa confiança em seu pensamento que Weber resgata ou tenta resgatar o melhor da "metodologia científica" (para

\begin{tabular}{|l|l|l|l|l|}
\multicolumn{1}{|c|}{ ISSN 2596-1314 } \\
\begin{tabular}{|l|l|l} 
CAMPOS NEUTRAIS \\
REVISTA LATINO-AMERICANA DE RELAÇÕES INTERNACIONAIS
\end{tabular} & Rio Grande & v. 3, n. 2 & p. 143-154 & Maio-Ago 2021 \\
\hline
\end{tabular}


as ciências humanas e sociais) e dos conceitos (ele é rigoroso ao propor, formular e discutir conceitos) para ter uma ciência social lógica, objetiva em que os múltiplos fatores se encontram relacionados e se explicam reciprocamente.

Sabendo que a verdade se perdera para o conhecimento e seu ceticismo corrosivo, dedicou-se ainda mais a conhecer o incognoscível. Nenhum assunto era estranho à sua mente perscrutadora, uma mente penetrante da qual nada escapava (DIGGINS, 1999, p. 66).

A Sociologia não nasce e morre com Weber. Mas o pensamento sociológico cresce, fortalece, renasce e humaniza com Weber. Ele propõe estudar o humano - nas suas relações sociais - em sua totalidade, nas suas diversas partes, complexidades... Weber explora o ser humano, na sua essência trágica, em que o agônico está presente, as angústias, o sofrimento e a aflição. A obra de Weber anuncia a faceta da agonia na política: a) marcada pela incerteza, pela imprevisibilidade, a qualquer momento algo - não previsto - mudará o curso dos acontecimentos, o roteiro traçado, planejado, idealizado; b) a constante oscilação entre a ordem e a crise; c) o conflito entre o possível e o desejável (o desejável que não é alcançado, e o possível que é difícil de ser conciliado); d) os sujeitos políticos que são mortais, falíveis, possuem limitadas escolhas e pouca ou quase nenhuma margem de ação.

\section{2) Como entender a tragédia?}

Como entender a tragédia? Podemos entender a tragédia como um mundo constituído de conflitos fundamentalmente insolúveis. A tragédia na política, portanto, é um conflito não solucionado e insolúvel. Ou seja, a postulação da inevitabilidade e insolubilidade do conflito. A animosidade de espírito é uma propensão da humanidade, diria Weber. Em qualquer ocasião substancial, frívola ou fantasiosa diferença, já é suficiente para acirrar paixões de inimizade e alimentar conflitos indissolúveis. Weber percebia isso nas relações humanas permeadas e temperadas com conflitos.

Sem dúvida, as grandes obras trágicas que têm marcado singularmente a subjetividade e o pensamento ocidentais encontram-se no pensamento agônico. E quando dizemos pensamento agônico, é a presença de elementos ligados a ansiedade, inquietação, angústia, perturbação, tormento, inconstância e colapso.

A angústia e a perturbação estão no pensamento trágico das grandes peças do teatro grego e shakespeariano, e vamos encontrar também no pensamento de Weber, Freud ou Walter Benjamin. Não podemos ignorar que o "espírito ocidental” é caracterizado pelo 


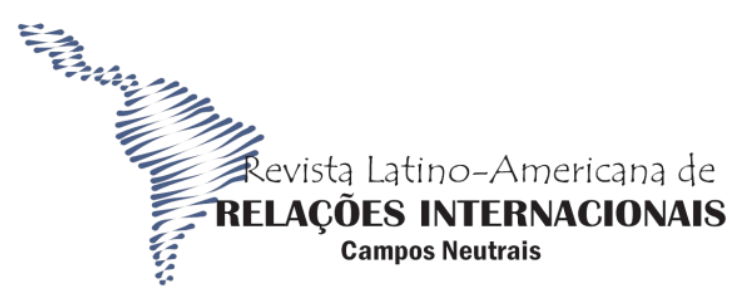

FURG

conflito. O conflito é o elemento constitutivo da política. O conflito, nada mais é que a realidade da política, seu factum, sua facticidade. É a matéria, o coração, o núcleo irredutível da política. O conflito e a permanência do conflito, a intrínseca "insolubilidade" da política nas negociações e fracassos da democracia política contemporânea no Ocidente é o que Weber já previa em seus rabiscos e escritos portentosos.

É nesse ponto que podemos perceber Weber como autor trágico.

Weber percebe o sentimento trágico da vida nos quais os princípios se opõem. Enquanto boa parte dos sociólogos busca princípios de integração e coesão, "Weber estava interessado no imiscível como a tensão, que veio a ocupar um lugar central em sua perspectiva" (DIGGINS, 1999, p. 88). Marx enxergou a divisão, a crise, os opostos em luta. Mas ele compreendia que a luta cessaria num determinado ponto histórico. Weber reconhecia o conflito como algo permanente e ligado a vida humana.

Muitos marxistas e marxianos - entre outros críticos maduros e imaturos - veem Weber como um acadêmico alemão das classes dominantes, mandarim universitário de linguagem complexa e confusa.

Apesar disso, Weber ainda continua a figurar nas referências das ciências sociais do século XX, ao lado de outros autores singulares como Freud, Gramsci, Lévi-Strauss ou Keynes.

Realmente Weber perscruta a área da política - poder do Estado e o monopólio uso da força; a dinâmica das burocracias, os diferentes tipos de liderança política. Ele oferece ao leitor as "potentes pulsações dos indivíduos que exercem atividades de governo e, também, as surdas movimentações das conjunturas relacionadas ao poder" (SILVEIRA, 2012, p. 13). Para Weber, o interesse, a força e a coerção caracterizavam todas as relações de poder. Como pontua Diggins (1999, p. 268):

Weber tendia a ver história plena de ocorrências por acaso, potencialidades e mutações, eventos únicos e possibilidades incondicionais, resultados irônicos e inícios fortuitos, tudo acrescentando sentindo e valor à forma pela quais os acontecimentos surgem e se desenvolvem.

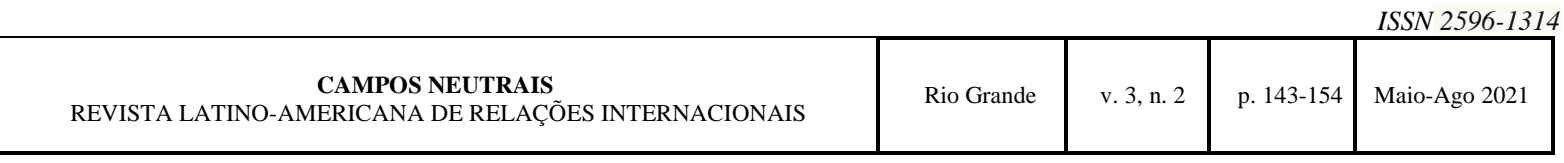




\section{3) Weber e os três elementos}

Podemos apontar três elementos, como afirma Juan F. Marsal (Apud WEBER, 2006), para ler Weber:

a) A ideia equivocada, mantida por ideólogos de direita, de que Weber é o "Marx da burguesia". "Ou dito de outra maneira: de que Weber refutou Marx e de que, sobretudo a sua obra $A$ ética protestante e o espírito do capitalismo, demonstrou contundentemente que Marx estava errado". No entanto, autores e especialistas na obra de Marx, consideram que Weber não pretendeu refutar Marx e que a obra dele, em muitos sentidos, é um refinamento e um aperfeiçoamento de Marx. E vale destacar que A ética protestante e o espírito do capitalismo é uma obra fraca, inconsistente, frágil de argumentos - sem dúvida a obra mais fraca, "conhecida" pelo grande público e apressada de Weber - e que foi refutada em muitos aspectos pelos historiadores.

b) A razão política da preeminência de Weber reside em ter sido um dos autores que serviu da base europeia para o lançamento do funcionalismo norte-americano, teoria sociológica predominante no mundo depois da II Guerra Mundial até meados dos anos 1960. Da amplidão de conhecimentos weberianos, os funcionalistas tomaram os que lhes eram mais favoráveis para o seu propósito de construir uma teoria universal, um Weber abstrato e metodológico, fora do seu contexto cultural alemão, que fosse o umbral da grande teoria funcionalista anglo-saxônica.

c) A obra weberiana possui um valor permanente. A visão de Weber sobre os conflitos na sociedade moderna foi moldada pelo entendimento da tragédia, que ele apropriou das obras de Nietzsche e Simmel, e pela descrição dos limites da responsabilidade moral, que ele desenvolveu a partir de seus estudos sobre o Calvinismo. As teses mais duradouras do pensamento Weberiano - poder, capitalismo, burocracia e ciência - são tão atuais e nos servem para ajudar a compreender os dilemas da contemporânea política brasileira. Para Weber, a política é intrinsecamente trágica, uma vez que possibilita o uso "diabólico" do poder; exercer atividade política é abdicar de toda pretensão à inocência e virtude e aceitar os encargos da responsabilidade e a presença traiçoeira do mal.

Para Marsal (2206), a obra de Weber não é compacta e unitária. É uma obra contraditória, cheia de ambiguidades e de paradoxos, como as próprias convicções do seu próprio autor.

Por isso Weber é historiador universal, não como expositor, como Ranke; nem como filósofo da história, como Hegel; nem como coletor de dados, 


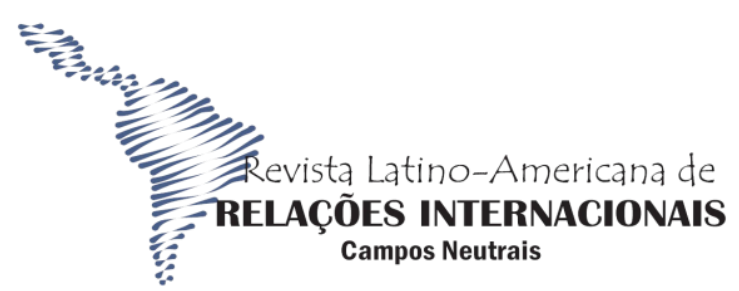

FURG

como Schmoller; nem como observador das figuras, como Burckhardt; mas como sociólogo. A exposição, a construção, a coleta, a visão servemlhe de meios de limitada importância. Na medida em que ele não se deixa envolver por nenhum desses recursos como uma meta, o mundo das coisas humanas se lhe apresenta de início como totalmente fragmentado para suas perguntas sobre as causas. Sua sociologia é histórica universal através da ascensão interminável rumo às questões radicais, para chegar pela compreensão às grandes decisões, às raízes últimas na mudança das coisas humanas. Ele quer compreender, a partir de fatores determináveis, como a existência humana chegou a ser. Ele quer saber, mas ao mesmo tempo quer esclarecer, para cada caso, o limite do saber. É por isso que, apesar de um conhecimento que provavelmente parecia aos outros como penetrando totalmente nas coisas, ele tem um persistente medo do real, que jamais é conhecido senão com respeito a algo (COHN, 2007, pp. 112-113).

Max Weber tinha uma extensa curiosidade: refletiu sobre assuntos tão variados quanto os camponeses russos e os índios de Oklahoma; tipos de poder através da história e possibilidades de liberdade numa era de burocracia; o animismo místico de religiões nãoocidentais e os mecanismos anti-espirituais do racionalismo ocidental; uma teoria da política que ressaltava a liderança e a responsabilidade ética e uma teoria da investigação científica que servia de caução contra intrusões éticas; o judaísmo antigo e o Torá, e as mulheres modernas e o erótico. Nenhum outro cientista social explorou tantos assuntos com um pensamento tão incansável e rico.

Weber extraiu dos Estados Unidos e da Europa, uma visão trágica da história. Outro exemplo da "trágica sensibilidade de Weber é quando ele nos mostra que mesmo os elevados ideais que escolhemos e praticamos estarão em conflitos com outros ideais" (DIGGINS, 1999, p. 32).

Por exemplo, um dos grandes temas de Weber é o capitalismo. O interesse pelo capitalismo levou Weber a investigar comparativamente as suas origens nos contextos sociais das grandes religiões mundiais. Esta tarefa gigantesca, comparável a muito poucas, tem uma motivação patriótica. Com foi indicado por alguns autores, como o inglês Giddens, nasce da sua preocupação pelo "capitalismo atrasado" alemão e pela forma como este se estava a processar. Por contraste, Weber usa os Estados Unidos. Os Estados Unidos,

\begin{tabular}{|l|l|l|l|l|} 
ISSN 2596-1314 \\
CAMPOS NEUTRAIS & Rio Grande & v. 3, n. 2 & p. 143-154 & Maio-Ago 2021 \\
REVISTA LATINO-AMERICANA DE RELAÇÕES INTERNACIONAIS & & \\
\hline
\end{tabular}


apresentados como a forma de sociedade capitalista mais antitradicional, como um aceite mescla de aristocracia e plutocracia.

As diferenças fundamentais com Marx é de fins, não de meios. Muitas vezes coincidirão na análise, mas há um ponto em que a diferença é essencial: para Marx, o capitalismo era irracional e indesejável; para Weber o capitalismo era a forma universal de modernização e a expressão mais alta da racionalização do homem ocidental. Essa diferença quase absoluta de Marx no respeitante à valoração do capitalismo dentro do processo histórico ocidental perde-se ao tratar os problemas de estratificação nos quais realmente Weber se torna um complemento qualificadíssimo da obra de Marx.

Outros dos aspectos de maior envergadura dos que emergem das profundas contradições weberianas é sua divisão da História. Pois embora Weber insista, nalguns textos, numa visão tipicamente conservadora da História como uma alternância entre períodos extraordinários ou de carisma e de períodos normais ou burocratização, essa concepção cíclica é, no entanto, desmentida noutros textos em que Weber apresenta a história unilateralmente, como um processo inexorável ao caminho da burocratização ou da racionalização do mundo, de uma forma tão irremediável como a que ele criticava a história progressista do marxismo, desde o reino da necessidade ao da liberdade.

Vemos um Weber contraditório que oscila entre uma concepção conservadora como a dos críticos da sociedade de massas, e uma visão negativa de profeta do desastre, na qual o mundo caminha para a "noite polar" e a "jaula de ferro" sem liberdade (eis a força do pensamento trágico para Weber); tão inexoravelmente, como Marx, outro grande filho da Ilustração, verá a caminhada em sentido oposto, para a libertação e o reino da liberdade. "Ao nos mostrar a historicidade da esperança de Marx, o próprio trágico sentido weberiano da história dramatiza a irreversibilidade do tempo" (DIGGINS, 1999, p. 28).

Conforme pondera Marsal (2006), outro aspecto proeminente no pensamento de Weber é a metodologia própria. É uma análise centrada no indivíduo e nas suas motivações - o ponto de vista Robinson Crusoé. Mais tarde, os sociólogos funcionalistas a exaltaram.

Weber opõe-se ao monocausalismo (que exemplifica na interpretação materialista da História) um pluricausalismo, que reflete o politeísmo de valores, em que não se pode dar prioridade à causa alguma. Neste sentido, as ideias em si não causam nada, mas são, como diz Weber, "guarda linhas da história", que dirigem às causas materiais e econômicas que, em última hipótese, são as que impelem o processo (MARSAL, 2006, p. 23). 


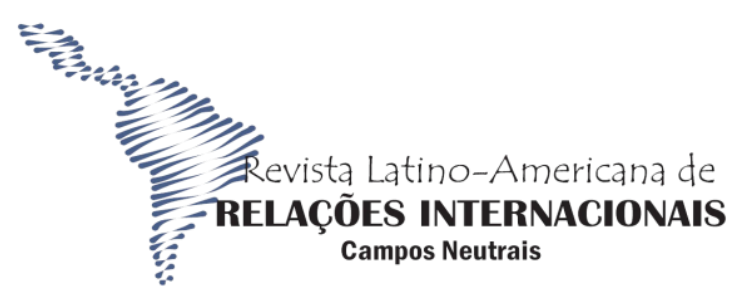

FURG

$\mathrm{Na}$ sua metodologia, Weber realça a neutralidade valorativa, um dos cavalos de batalha dos metodólogos funcionalistas. Isso significa que o analista social se coloque numa total independência em relação aos seus próprios valores e motivações ideológicas.

\begin{abstract}
A neutralidade valorativa da ciência não significa, pois, para Weber, a interdição de valorar na vida, mas pelo contrário: é a paixão do valorar e do querer que engendra, como seu próprio esclarecimento e auto-educação, a legítima objetividade da pesquisa. A neutralidade valorativa também não quer dizer, para ele, que valorações efetivamente feitas ou possíveis não possam ser objeto de pesquisa mas, pelo contrário, elas constituem o objeto essencial para a investigação das coisas humanas; é apenas através da neutralidade valorativa que vem a existir aquela reserva no exame de cada valoração e do seu sentido, de sua origem e de suas consequências que efetivamente as traz aos olhos e à consciência. A neutralidade valorativa não significa para ele, finalmente, que a escolha dos problemas a serem pesquisados não repouse sobre valorações; pelo contrário, a decisão valorativa acerca daquilo que me atinge é precondição para a legítima paixão na pesquisa (COHN, 2007, pp. 117-118).
\end{abstract}

Por fim, os caminhos da perspectiva metodológica weberiana levam-no a caminhos irresolúveis. Por isso cria o método ou artificiosismo dos "tipos ideais", que é uma espécie de construção utópica com as variáveis mais sobressalentes de qualquer situação social, espécie de construção hipotética para ver os aspectos mais destacados de um fenômeno social na sua totalidade que ainda necessitam de verificação.

\title{
4) Weber e o pensamento trágico
}

Um termo que encaixa bem nas inquirições e a produção intelectual de Weber é "antinomia", a oposição inevitável entre os princípios que são essenciais à vida, embora antagonísticos entre si. Essa ambiguidade é fruto de sua imaginação antinômica que revela uma rara sensibilidade. Um exemplo da trágica sensibilidade de Weber é quando ele nos mostra que mesmo os elevados ideais que escolhemos e praticamos estarão em conflito com outros ideais. Aqui reside um ponto trágico em Weber.

\begin{tabular}{|l|c|c|c|c|}
\hline $\begin{array}{l}\text { ISSN 2596-1314 } \\
\text { CAMPOS NEUTRAIS }\end{array}$ & Rio Grande & v. 3, n. 2 & p. 143-154 & Maio-Ago 2021 \\
\hline
\end{tabular}


Para Weber, a política moderna exigia algo próximo de um "renascimento" da tragédia, e a tragédia, como a imitação de ações nobres, não se pode esperar que surja da democracia, onde simplesmente suportamos o medíocre enquanto esperamos o extraordinário. A ideia weberiana da tragédia está longe da estratégia teatral de retratar uma ascensão dramática e uma queda calamitosa, embora realmente envolva provações de liderança, intenções mal compreendidas e ironias de ação. Mais especificamente, o senso da tragédia, em Weber, consiste em dois componentes. Primeiro, penetrar as ilusões e as racionalizações da vida das pessoas, que se permitem aproximar do poder em nome da liberdade; ou, uma autodecepção diferente, perder uma emoção profunda, como o amor e, em vez de sofrer a perda, legitimá-la usando a razão como racionalização psicológica. Em segundo lugar, uma compreensão de que não há nenhum sentido verdadeiro do mundo senão as interpretações e valores que trazemos para ele, e escolhemos nossos valores "às cegas", sem um conhecimento objetivo e à exclusão de outros valores e compromissos. A tragédia envolve o conflito de escolhas irreconciliáveis, mas o conhecimento de uma situação trágica pode também ser educativo, no sentido em que revela os impulsos controladores de nossos pensamentos que impedem o encontro da mente consigo mesma (DIGGINS, 1999, p. 308).

"Weber nos permite sentir o "trágico abismo entre o real e o ideal (o possível e o desejável), entre a adaptação e aspiração, entre os fatos comuns da existência natural e os anseios do espírito" (DIGGINS, 1999, p. 13).

Nas próprias palavras de Weber: "O homem não teria atingido o possível, se não houvesse reiteradamente tentado alcançar o impossível". Weber invoca a chamada “capacidade negativa”, como o poeta John Keats (APUD DIGGINS, 1999) definiu: "uma capacidade para permanecer nos mistérios, nas incertezas e nas dúvidas, sem nenhuma busca irritante de fatos ou razão". Atualmente, Weber teria tido pouca ou nenhuma paciência com a recente "virada linguística", no pensamento moderno.

De acordo com Diggins (1999, p. 14):

Para Weber, a realidade era existencial, não simplesmente textual, e os dualismos que ele discernia tinham menos a ver com descrição verbal do que com uma condição humana que deve enfrentar escolhas irreconciliáveis, decisões morais em um mundo imoral, um mundo irracional demais, mesmo para certeza racional da retórica.

O pensamento de Weber é trágico e irônico, pois, concebe a ideia de Shakespeare e da Bíblia - "a política não pode elevar-se à redenção espiritual, pois deve colaborar com o poder e suas corrupções, e assim nela não pode haver nenhum sabor de salvação" (DIGGINS, 1999, p. 16). 


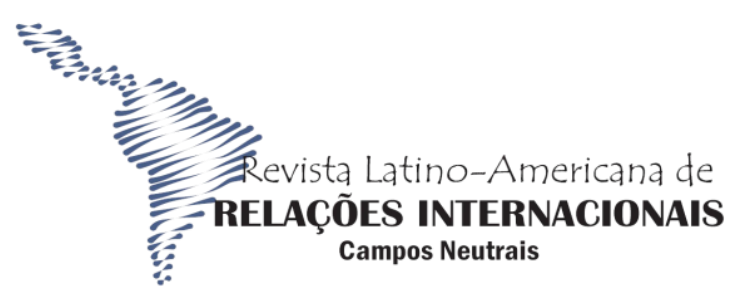

FURG

Weber é um autor trágico, pois, ele aponta como afirma Chaia apud Silveira (2012, p. 16): "persistência das tensões tanto no cotidiano quanto na política, pois na vida e na sociedade os conflitos são agônicos". Ou seja, "a política como tragédia aponta para a insuficiência das práticas políticas e clarifica que o governante (ou o indivíduo) não tem controle absoluto de suas ações" (CHAIA apud SILVEIRA, 2012, p. 16).

Weber, como autor trágico, percebe o mundo marcado pela criação e destruição, alegria e sofrimento, conquista e perda, desejo de poder e corrupção, ordem e caos, estabilidade e instabilidade, glória e fracasso.

Retomar o pensamento trágico em Weber, na atualidade, como pondera Silveira (2012, p. 151): “insere-se numa realidade fragmentada, em pedaços, como política, amizade, amor, loucura, sonho, ambição, religião e morte, e está em constante e absurdo movimento". A política é trágica. Weber é um autor trágico. Como avalia Rodrigues $(2019$, p. 8): "na política, nos forjamos como somos no combate, e pela força”. A política, portanto, se caracteriza pelo conflito entre o desejável e o possível.

Weber percebe que no reino da política, ela contém em si mesma o potencial permanente de gerar a usurpação, a violência e a guerra. Para Weber, "a política é intrinsecamente trágica, uma vez que possibilita o uso "diabólico" do poder, exercer atividade política é abdicar de toda pretensão à inocência e virtude e aceitar os encargos da responsabilidade e a presença traiçoeira do mal" (DIGGINS, 1999, p. 30).

"E queiramos ou não, a lógica própria e imperiosa da política trata desse desgastante embate que estão envolvidos governantes e governados" (CHAIA apud Silveira, 2012, p. 17).

\section{REFERÊNCIAS}

COHN, Gabriel (org). Sociologia: para ler os clássicos. Rio de Janeiro: Azougue, 2007.

\begin{tabular}{|c|c|c|c|c|}
\multicolumn{1}{|c|}{ ISSN 2596-1314 } \\
\begin{tabular}{|l|l|l} 
CAMPOS NEUTRAIS \\
REVISTA LATINO-AMERICANA DE RELAÇÕES INTERNACIONAIS
\end{tabular} & Rio Grande & v. 3, n. 2 & p. 143-154 & Maio-Ago 2021 \\
\hline
\end{tabular}


DIGGINS, John Patrick. Max Weber: a política e o espírito da tragédia. Trad. de Liszt Vieira e Marcus Lessa. Rio de Janeiro: Record, 1999.

MARSAL, Juan F. Por que Weber? In: WEBER, M. Ciência e política: duas vocações. São Paulo: Martin Claret, 2006. p.11-22.

RINESI, Eduardo. Política e tragédia: Hamlet, entre Hobbes e Maquiavel. Trad. M. Encarnación Moya. Rio de Janeiro: Beco do Azougue, 2009.

SILVEIRA, José Renato Ferraz. A tragédia da política em Ricardo III. Rio de Janeiro: Beco do Azougue, 2012.

SILVEIRA, José Renato Ferraz. A tragédia da política (Relações Internacionais). 1 ed. Curitiba: Appris, 2019.

WEBER, Max. Ciência e Política: duas vocações. Trad. Jean Melville. São Paulo: Martin Claret, 2006. 